\title{
A Proposed Mediated Path between Gender and Posttraumatic Growth: The Roles of Empathy and Social Support in a Mixed-Age Sample
}

\author{
Rhonda J. Swickert, James B. Hittner, Aasha Foster \\ Department of Psychology, College of Charleston, Charleston, USA \\ Email: swickertr@cofc.edu \\ Received August $9^{\text {th }}, 2012$; revised September 10 $0^{\text {th }}, 2012$; accepted September $27^{\text {th }}, 2012$
}

\begin{abstract}
Social support coping has been shown to mediate the relationship between gender and posttraumatic growth. This study examined whether empathy also serves as a significant mediator in this relationship, potentially as a precursor to social support coping. Participants $(N=156)$ were recruited on a college campus and at a retirement community. They completed questionnaires that assessed the variables of interest and they provided information regarding a stressful life event. Single-mediator path analytic models indicated that both empathy and social support were significant mediators. The full multiplicative mediational path from gender to empathy to support to growth was significant, but this finding was largely driven by the strong mediational effect of empathy. These findings suggest that although both empathy and social support coping are significant mediators in the relationship between gender and stress related growth, of the two constructs, empathy appears to exert a stronger mediational effect.
\end{abstract}

Keywords: Gender; Posttraumatic Growth; Empathy; Social Support; Coping

\section{Introduction}

Posttraumatic growth can be understood as the occurrence of positive psychological change that can come about when individuals respond to highly challenging life events (Tedeschi \& Calhoun, 2004). Previous studies have shown that gender serves as a significant predictor of growth following trauma (Linley \& Joseph, 2004; Swickert \& Hittner, 2009). Although not all studies have reported a relationship between these variables (Cryder, Kilmer, Tedeschi, \& Calhoun, 2006), many studies have shown that females, as compared to males, are more likely to report benefit and growth following a traumatic event (Bellizzi, 2004; Salo, Qouta, \& Punamäki, 2005; Swickert, DeRoma, \& Saylor, 2004), and a recent meta-analysis supports this conclusion (Vishnevsky, Cann, Calhoun, Tedeschi, \& Demakis, 2010). In determining why gender is associated with posttraumatic growth, Swickert and Hittner (2009) showed that social support coping plays a mediational role in the relationship between these two variables. The current study aims to replicate this finding and extend this work by examining whether empathy might also serve as a mediator in the relationship between gender and posttraumatic growth.

Regarding the mediating role of social support, females naturally seek out others during times of stress (Eagly \& Crowley, 1986; Taylor et al., 2000), and as a result of these supportive experiences, the traumatized person may over time see others in more positive ways and may feel more confident in responding to the stressful event (Tedeschi \& Calhoun, 2004). Indeed, in examining the mediational role of social support in the relationship between gender and posttraumatic growth, Swickert and Hittner (2009) found that social support enhanced one's feelings of closeness with family members as well as other social network members. In coping with a traumatic event, the individual may need a great deal of emotional support, as well as other forms of assistance. Thus, when the traumatized person seeks out support and it is provided, this often leads the individual to see others in more positive ways and to grow closer to the people in their support network.

In addition to social support, it is possible that empathy might also mediate the relationship between gender and posttraumatic growth. Definitions of empathy vary, but for the purpose of the present study we define empathy as entailing both an understanding of another's emotional state coupled with the tendency to feel emotional responses that are similar to another person's emotional responses (Lawrence, Shaw, Baker, BaronCohen, \& David, 2004). Although females do not necessarily show greater empathic accuracy than do males (Ickes, Gesn, \& Graham, 2000), there is a general consensus that females display greater empathy when responding to others than do males (Chakrabarti \& Baron-Cohen, 2006). Recent studies in social neuroscience suggest that the estrogen-linked neuropeptide oxytocin contributes to empathic responding (Carter et al., 2009). Other research has shown that portions of the "pain matrix" (i.e., the anterior ansula and the anterior cingulate) are less active in men, compared to women, when participants view an individual in pain (Singer et al., 2004). Additionally, females self-report higher levels of empathy than do males (Davis, 1994), and girls seem to develop a theory of mind earlier than do boys (Putallaz, Hellstern, Sheppard, Grimes, \& Glodis, 1995; Walker, 2005). Finally, research also has shown that females tend to be more responsive than males when those around them experience stress (Neff \& Karney, 2005). Taken together, this evidence suggests an important relationship between gender and empathy.

How might the gender-empathy association shed light on the finding that females report greater posttraumatic growth than 
males? One model to consider is that empathy has a direct mediational role in accounting for the association between gender and stress-related growth. Researchers have suggested that individuals who are more prosocial in their orientation (e.g., more empathic and nurturing) may be better equipped to manage traumatic life events (Staub \& Vollhardt, 2008; Woike \& Matic, 2004). That is, it is believed that the act of empathizing and helping others who are coping with stressful experiences provides a model for the traumatized individual in terms of self-care during a personally-experienced stressful or traumatic event. However, an alternate model to consider in regards to the mediational role of empathy is that empathy may serve as a precursor to social support coping in the mediational path. Empathy has been shown to strengthen one's ties with others (Sullivan, Pasch, Johnson, \& Bradbury, 2010), and enhance relationship satisfaction (Cramer, 2003; Davis \& Oathout, 1987). Furthermore, those who are higher in empathy tend to turn to others when coping with stressors in the environment (McWhirter, Besett-Alesch, Horibata, \& Gat, 2002). As such, those who are more empathic should have a stronger social support system to rely on when coping with stressful life circumstances. Given the mediational role of social support in addressing the relationship between gender and posttraumatic growth, it seems then reasonable to consider a multi-mediated, or multiplicative, path that includes both empathy and social support coping as significant mediators in the relationship between gender and stress-related growth.

In addressing the associations among gender, the proposed mediators, and posttraumatic growth, we identified three major goals. First, we examined whether the mediational role of social support coping in accounting for the relationship between gender and posttraumatic growth could be replicated. Second, we addressed whether empathy also serves as a significant mediator in the relationship between these two variables. Third, we tested whether a multi-mediated path (multiplicative effect) could best account for the relationship between gender and growth. In this model we predicted that females, as compared to males, would report greater levels of empathy. Higher levels of empathy would, in turn, be associated with greater levels of social support coping and greater levels of social support would be predictive of higher levels of posttraumatic growth. Finally, in addressing these goals we had the opportunity to sample participants who were tested as part of a larger study that examined age differences in stress-coping processes. In that regard, we collected data from a college-student population (aged 18 to 35 ) and from a retirement community (aged 55 to 100).

Although age differences in stress-coping were not the focus of the present inquiry, we chose to utilize the full sample for two reasons. First, the process of combining the two distinct subsamples (college students and retirees) creates a more heterogeneous sample, and the results derived from this sample might, in turn, have greater generalizability. Second, because the combined sample size is, of course, larger than either subsample, the standard errors of the parameter estimates will be smaller thereby giving us greater statistical power to detect potentially meaningful effects. The principal caveat associated with combining the two subsamples concerns the possible confounding role of age (i.e., the age disparities between the two subsamples). However, as discussed below in the Method section, we have effectively dealt with the age confound issue by 1) removing the influence of age on the dependent, or criterion, variable by creating an age-residualized dependent variable, and 2) conducting data diagnostics (i.e., between-sample tests of covariance matrices) in order to justify pooling the two subsamples. The details of these procedures are described below.

\section{Method}

\section{Participants}

One hundred and fifty-six participants were recruited from two different settings: students from a college campus $(N=94)$ and older adults in a retirement community $(N=62)$. Females constituted $61 \%$ of the sample. The participants were primarily White $(90 \%)$, although both Asians and Blacks were represented $(10 \%)$. The college students ranged from 18 to 35 years of age $(M=20.5, S D=2.5)$ and the retirees ranged in age from 55 to $100(M=74.8, S D=7.2)$. The two subsamples did not differ on the basis of gender $\left(\chi^{2}(1)=.553, p=.457\right)$ or ethnicity $\left(\chi^{2}(4)=5.337, p=.254\right)$.

\section{Materials}

The Perceived Benefits questionnaire (PB; McMillen \& Fisher, 1998) was used to measure posttraumatic growth. Participants are asked to complete a 44 -item questionnaire ( 8 of which are filler items), using a 5-point Likert scale. Higher scores on this scale are indicative of greater posttraumatic growth. The internal reliability of the PB in this study was high (Cronbach's alpha $=.94)$. Validity information regarding this scale can be found in McMillen and Fisher (1998).

The Coping Strategy Indicator (CSI; Amirkhan, 1990) was used to assess social support seeking as a coping response. The overall scale is comprised of 33 items, and 11 of these items make up the support seeking subscale. In completing the CSI, participants are asked to think about a stressful event and to respond to statements about their coping responses using a 3point Likert-type scale. Higher scores on the support seeking subscale are indicative of greater social support seeking. In the current study the internal consistency of the subscale was .90 . Information regarding the validity of this questionnaire can be found in Amirkahn (1990).

The short version of the Empathy Quotient Scale (EQS; Muncer \& Ling, 2006) was used to assess empathy. This scale assesses the degree to which the individual understands how another feels, whether they feel a similar emotional state as another person, and whether they can interact with others in an empathic manner. The internal consistency of this scale was adequate $($ alpha $=.67)$. A discussion of the psychometric properties of the EQS can be found in Muncer and Ling (2006).

\section{Procedure}

Participants were solicited from a college campus and from a retirement community, both of which are located in the southeastern region of the United States. Both groups were given a packet of materials that included an informed consent form, a demographic form and the survey materials. For the campus sample, participants received research credit for participating in the study and they completed the survey in group testing sessions. For the retirement community sample, participants were instructed to complete the materials in the privacy of their homes/rooms. After granting informed consent but before completing the survey instruments, participants were instructed to recall a distressing experience that they had encountered within 
the past year and to respond to the PB and CSI questionnaires with this event in mind. Examples of distressing events included death of a loved one, financial concerns, health problems, and relationship conflict. Participants also were asked to rate the perceived stressfulness of the event using a 4-point Likert scale, which ranged from "not at all stressful" to "extremely stressful". For the retiree subsample, the mean stressfulness rating was 3.42 , and $89 \%$ of the older adults indicated that the event was "moderately stressful" or "extremely stressful". Regarding the college students, the mean stressfulness rating was 3.62 , and $95 \%$ of the younger adults indicated that the event was "moderately stressful" or "extremely stressful". After completing the packet, residents from the retirement community were instructed to return the materials in a sealed envelope to the social worker at the facility.

\section{Data Analyses}

Before examining the mediational hypotheses, we statisticcally removed the potential confounding influence of age from the Perceived Benefits dependent variable. This procedure was done for each subsample separately. Removing the influence of age (i.e., the statistical covariation with age) is important given previous research showing that participant age can affect selfreports of posttraumatic growth (Bellizzi, 2004; Linley \& Joseph, 2004; Widows, Jacobsen, Booth-Jones, \& Fields, 2005). In addition to age, we also removed from perceived benefits the potential confounding influence of perceived stressfulness of the reported event. This is important because level of perceived stress also can affect self-reports of posttraumatic growth (Linley \& Joseph, 2004). The statistical influence of these two variables was removed from the dependent variable by creating a residualized version of perceived benefits. This was accomplished through multiple regression by regressing perceived benefits on both age and perceived stressfulness, saving the unstandardized residuals from the analysis, and then treating the doubly-residualized (i.e., residualized for both age and perceived stressfulness) perceived benefits scale as the new dependent variable. The residualized perceived benefits scale can be thought of as the perceived benefits variable that remains after controlling for, or removing the variance associated with, age and perceived stressfulness.

After residualizing the perceived benefits scale for each subsample separately, we then examined the comparability of the two subsamples by assessing whether the pattern of covariances among the four variables in the full multi-mediated model (i.e., gender, empathy, social support, residualized perceived benefits) was non-significantly different across the two groups (college students versus older adults). If the covariances among the target variables are similar, then the two groups can be combined. The result of Box's $M$ Test, which tests the equality of covariance matrices across groups, was non-significant (Box's $M=$ $16.94, F(10,73493.3)=1.64, p=0.088)$, indicating that it is statistically justifiable to pool the two subsamples.

To test for statistical mediation, we used the product of coefficients approach, which calculates indirect effects by multiplying the path coefficients that link $X$ to $Y$ through the specified mediator, or mediators, $M$. For each indirect effect, a point estimate is generated along with a corresponding $95^{\text {th }}$ percentile bias-corrected and accelerated bootstrap confidence interval. Because the expected sampling distribution of indirect effects is skewed (Preacher and Hayes, 2008), normal theory tests of significance, such as Sobel's test, are not recommended. Instead, bootstrap resampling approaches are preferred (see Hayes, Preacher, \& Myers, 2011). An indirect effect is considered statistically significant at $p<.05$ when the lower and upper limits of the $95^{\text {th }}$ percentile bootstrap interval exclude zero. In all of our mediation analyses we generated 5000 bootstrap resamples for each indirect effect in order to ensure stable confidence intervals. In our presentation of the mediation results, indirect effects are denoted as IE followed, in parentheses, by the lower and upper $95^{\text {th }}$ percentile bootstrap confidence intervals. All mediation analyses were conducted using Andrew Hayes' indirect and medthree SPSS macro programs (available at www.afhayes.com).

\section{Results}

Descriptive data (means, standard deviations) for gender, empathy, social support and residualized perceived benefits (henceforth just "perceived benefits"), along with Pearson correlations among the four variables, are presented in Table 1.

Although the correlations between perceived benefits and both empathy and social support are significant, the correlation between perceived benefits $(\mathrm{Y})$ and gender $(\mathrm{X})$ is not. In the language of path analytic modeling, the correlation between $\mathrm{X}$ and $\mathrm{Y}$ - or the total effect of $\mathrm{X}$ on $\mathrm{Y}$ - equals the sum of the direct and indirect effects that link $\mathrm{X}$ to $\mathrm{Y}$. In some cases, or in some research scenarios, the direct effect of $\mathrm{X}$ on $\mathrm{Y}$ might be most important. In other cases the indirect effects might best capture the association between $\mathrm{X}$ and $\mathrm{Y}$. In yet other scenarios the indirect effects might exert countervailing influences, thereby rendering the total effect, or the Pearson correlation, between X and Y non-significant (see Hayes, 2009, for a recent review of total, direct, and indirect effects). The growing consensus among research methodologists is that a statistically significant bivariate correlation (total effect) between $\mathrm{X}$ and $\mathrm{Y}$ is not a necessary precondition to performing mediational modeling in an effort to uncover potentially important indirect effects (see Hayes, 2009; MacKinnon, Krull, \& Lockwood, 2000; Shrout \& Bolger, 2002). In fact, as Hayes (2009: p. 415) wrote: "A failure to test for indirect effects in the absence of a total effect can lead you to miss some potentially interesting, important, or useful mechanisms by which $\mathrm{X}$ exerts some kind of effect on Y".

\section{Path Analyses}

Social Support Coping and Empathy as Individual Mediators.

Table 1.

Descriptive statistics and Pearson correlations among the study variables $(N=156)$.

\begin{tabular}{cccccc}
\hline & & Gen & SSC & PBS & EQT \\
\hline Mean (SD) & Gen & 1 & $-.213^{* *}$ & -.123 & $-.356^{* *}$ \\
$24.20(5.75)$ & SSC & & 1 & $.302^{* *}$ & $.413^{* *}$ \\
$0.00(21.17)$ & PBS & & & 1 & $.313^{* *}$ \\
$31.49(4.03)$ & EQT & & & & 1 \\
\hline
\end{tabular}

Note: ${ }^{* *} p<.01$, two-tailed. Study Variables: Gen $=$ Gender $(1=$ Female, $2=$ Male), $\mathrm{SSC}=$ Social Support Coping, $\mathrm{PBS}=$ Perceived Benefits Scale, EQT = Empathy Quotient Total. The mean of PBS is 0.00 because PBS is a residualized variable (see text for details). The mean of a normal distribution of residuals is always zero. 
Social support coping significantly mediated the association between gender and perceived benefits, IE $=-2.67(-6.24$, -.66). Similarly, empathy significantly mediated the link between gender and perceived benefits, IE $=-4.80(-8.99,-2.05)$. In comparing the magnitudes of the two indirect effects, the point estimate for empathy $(-4.80)$ is $44.3 \%$ larger than is the point estimate for social support (-2.67).

Empathy and Social Support Coping as a Multiplicative Mediator. The question addressed in this case is whether gender influences overall perceived benefits by way of both empathy and social support. In particular, the model posits a predictive chain whereby gender influences empathy, empathy then influences social support coping, and social support coping then influences perceived benefits. Results indicated a significant multiplicative mediational path, IE $=-1.25(-2.82,-.10)$. Of the two constituent single-mediator paths, only empathy statistically mediated the influence of gender on perceived benefits, $\mathrm{IE}=-3.52(-7.07,-.72)$. This finding suggests that when empathy and social support coping are directly pitted against each other as putative mediators of the gender-perceived benefits association, empathy emerges as the more important mediator. The individual mediator models for social support coping and empathy, and the full multiplicative mediator model, are presented in Figure 1.

\section{Discussion}

The purpose of this study was to extend our understanding of the variables that mediate the association between gender and posttraumatic growth. Results from the single-mediator models indicated that both social support coping and empathy significantly mediated the association between gender and perceived benefits, with females reporting greater levels of social support and empathy, and greater levels of each mediator, in turn, predicted higher levels of perceived benefits (i.e., greater posttraumatic growth). The significant finding regarding social support coping replicates previous research on this topic (Swickert \& Hittner, 2009). However, the strength of this replicated finding is tempered by the results of the multi-mediated path analysis. In this multiple mediation model, empathy exerted a stronger mediational effect (both individually and in driving the significant multiplicative indirect effect), than did social support coping. As such, these findings indicate that empathy plays a more prominent role than social support in explaining the association between gender and posttraumatic growth.

In the field of social psychology, empathy is a concept that is often discussed in the context of prosocial behavior because empathy has been shown to increase helping behavior that is

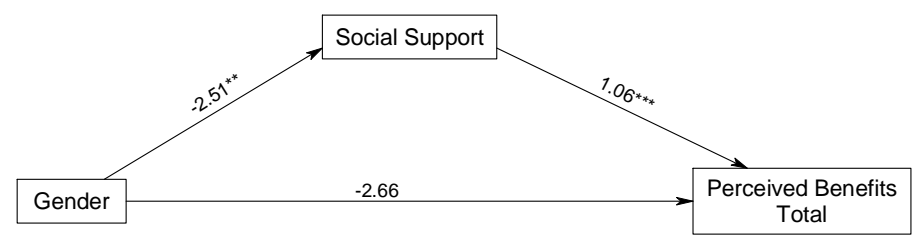

$\star \star \mathrm{p}<.01, * \star \star \mathrm{p}<.001$, two-tailed.

Indirect effect of Social Support $=-2.67$, Bootstrap $95 \% \mathrm{Cl}=-6.24,-.66$

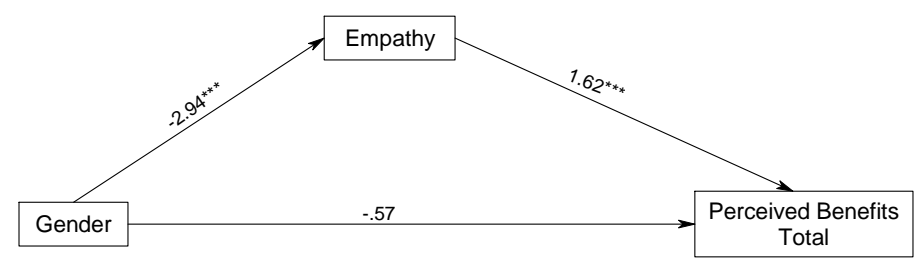

$\star \star \star p<.001$, two-tailed.

Indirect effect of Empathy = -4.80, Bootstrap 95\% $\mathrm{Cl}=-8.99,-2.05$.

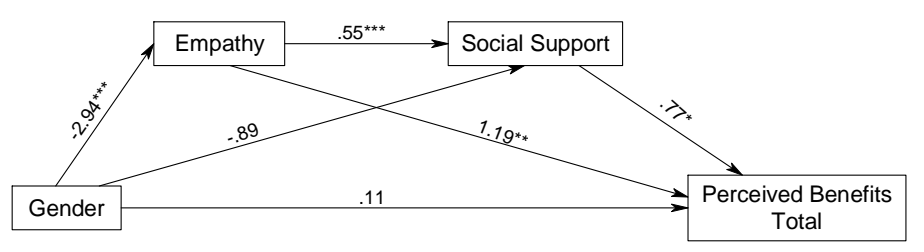

${ }^{*} \mathrm{p}<.05,{ }^{* \star} \mathrm{p}<.01,{ }^{\star \star \star} \mathrm{p}<.001$, two-tailed.

Indirect effect of Empathy $=-3.52$, Bootstrap $95 \% \mathrm{Cl}=-7.07,-.72$.

Indirect effect of Social Support $=-.68$, Bootstrap $95 \% \mathrm{Cl}=-2.78, .83$

Multiplicative Indirect effect of Empathy and Social Support $=-1.25$, Bootstrap $95 \% \mathrm{Cl}=-2.82,-.10$

Figure 1.

Individual mediator models for social support coping and empathy, and the full multiplicative mediator model. 


\section{R. J. SWICKERT ET AL.}

directed towards others (Batson, 1991; Toi \& Batson, 1982). It is perhaps ironic, then, that empathy also plays a protective role when the individual is responding to their own difficult life circumstances. In fact, some theorists believe that empathy should be considered a coping technique, as it is a process that helps the individual to effectively manage stress (O'Brien, DeLongis, Pomaki, Puterman, \& Zwicker, 2009), perhaps by facilitating social bonding and support seeking (Shirtcliff et al., 2009). In the present study, seeking of social support served as the measure of social support coping, and it was a significant component of the multiplicative mediational model. However, other measures of social support that may also prove relevant in explaining the gender-empathy-growth pathway include relationship satisfaction, as well as measures of functional social support and received social support (Hittner \& Swickert, 2001).

In addition to the empathy-social support multiplicative mediational model, the influence of empathy on stress-related growth also may operate through a different coping process. That is, it is believed that the act of empathizing and helping others who are coping with stressful experiences provides a model for the traumatized individual in terms of self-care during a personally-experienced stressful or traumatic event (Staub \& Vollhardt, 2008; Woike \& Matic, 2004). Thus, perhaps empathy operates through problem solving coping, as well as through support seeking. Recent research does suggest that empathy facilitates more effective problem solving coping, and this effect has been demonstrated with both adolescent and adult samples (deWied, Branje, \& Meeus, 2007; Sullivan, Pasch, Johnson, \& Bradbury, 2010). As such, future work in this area may want to examine whether, in the context of challenging life circumstances, empathy influences greater postraumatic growth through problem solving coping, a factor that has been associated with trauma-related growth (Bellizzi \& Blank, 2006).

Relative to previous research, the current study provides more detailed information regarding the factors that influence the association between gender and posttraumatic growth. However, there are some limitations to the present work that should be considered. First, because the study was cross-sectional we are unable to make definitive causal statements regarding the temporal linkages among the constructs examined in this study. Nevertheless, for reasons that were outlined earlier in the paper, we believe that our hypothesized model has good theoretical and empirical grounding in the literature. That being said, it should be noted that other viable pathways regarding the association between empathy and posttraumatic growth may exist (e.g., through problem solving coping), and future longitudinal studies in this area are needed to confirm the causal relationships among these variables. It also would be interesting to examine, perhaps by using experience sampling methodology, how it is that empathic responding increases one's level of posttraumatic growth. For instance, when one listens empathically to others, does that lead individuals to feel more comfortable talking about their own problems too? Does this process then allow for more active, problem solving coping? Clearly, there are many questions that remain regarding the role of empathy in influencing posttraumatic growth.

In summary, we found that both empathy and social support coping independently mediate the association between gender and posttraumatic growth. However, of these two mediators, empathy seems to play a more prominent role in accounting for the association between gender and growth. In essence, the capacity for empathy appears not only to help those around us, but it benefits ourselves as well. Because females, relative to males, tend to respond more empathically to others, they appear to extract greater benefit from the positive connection between empathy and posttraumatic growth.

\section{REFERENCES}

Amirkahn, J. (1990). A factor analytically derived measure of coping: The Coping Strategy Indicator. Journal of Personality and Social Psychology, 59, 1066-1074. doi:10.1037/0022-3514.59.5.1066

Batson, C. (1991). The altruism question: Toward a social-psychological answer. Hillsdale, NJ: Erlbaum.

Bellizzi, K. (2004). Expressions of generativity and posttraumatic growth in adult cancer survivors. International Journal of Aging and Human Development, 58, 267-287.

doi:10.2190/DC07-CPVW-4UVE-5GK0

Bellizzi, K., \& Blank, T. (2006). Predicting posttraumatic growth in breast cancer survivors. Health Psychology, 25, 47-56. doi: 10.1037/0278-6133.25.1.47

Cadell, S., Regehr, C., \& Hemsworth, D. (2003). Factors contributing to posttraumatic growth: A proposed structural equation model. American Journal of Orthopsychiatry, 73, 279-287. doi:10.1037/0002-9432.73.3.279

Carter, C., Harris, J., \& Porges, S. (2009). Neural and evolutionary perspectives on empathy. In J. Decety, \& W. Ickes (Eds.), The social neuroscience of empathy (pp. 169-182). Cambridge, MA: The MIT Press.

Chakrabarti, B., \& Baron-Cohen, S. (2006). Empathizing: Neurocognitive developmental mechanisms and individual differences. Progress in Brain Research, 156, 403-417. doi:10.1016/S0079-6123(06)56022-4

Cramer, D. (2003). Facilitativeness, conflict, demand for approval, self-esteem, and satisfaction with romantic relationships. The Journal of Psychology, 137, 85-98. doi:10.1080/00223980309600601

Cryder, C., Kilmer, R., Tedeschi, R., \& Calhoun, L. (2006). An exploratory study of posttraumatic growth in children following a natural disaster. American Journal of Orthopsychiatry, 76, 65-69. doi:10.1037/0002-9432.76.1.65

Davis, M. (1994). Empathy: A social psychological approach. Madison, WI: Westview Press.

Davis, M., \& Oathout, H. (1987). Maintenance of satisfaction in romantic relationships: Empathy and relational competence. Journal of Personality and Social Psychology, 53, 397-410. doi:10.1037/0022-3514.53.2.397

De Wied, M., Branje, S., \& Meeus, W. (2007). Empathy and conflict resolution in friendship relations among adolescents. Aggressive Behavior, 33, 48-55. doi:10.1002/ab.20166

Eagly, A., \& Crowley, M. (1986). Gender and helping behavior: A meta-analytic review of the social psychological literature. Psychological Bulletin, 100, 283-308. doi:10.1037/0033-2909.100.3.283

Erikson, E. (1963). Childhood and society (2nd ed.). New York: Norton.

Hayes, A. F. (2009). Beyond Baron and Kenny: Statistical mediation analysis in the new millennium. Communication Monographs, 76, 408-420. doi:10.1080/03637750903310360

Hayes, A. F., Preacher, K. J., \& Myers, T. A. (2011). Mediation and the estimation of indirect effects in political communication research. In E. P. Bucy, \& R. L. Holbert (Eds.), Sourcebook for Political Communication Research: Methods, measures and analytical techniques (pp. 434-465). New York: Routledge.

Hittner, J. B., \& Swickert, R. J. (2001). Modeling functional and structural social support via confirmatory factor analysis: Evidence for a second-order global support construct. Journal of Social Behavior and Personality, 16, 69-80.

Ickes, W., Gesn, P., \& Graham, T. (2000). Gender differences in empathic accuracy: Differential ability or differential motivation? Personal Relationships, 7, 95-109.

Lawrence, E., Shaw, P., Baker, D., Baron-Cohen, S., \& David, A. 


\section{R. J. SWICKERT ET AL.}

(2004). Measuring empathy: Reliability and validity of the Empathy Quotient. Psychological Medicine, 34, 911-919. doi: $10.1017 / \mathrm{S} 0033291703001624$

Linley, P. A., \& Joseph, S. (2004). Positive change following trauma and adversity: A review. Journal of Traumatic Stress, 17, 11-21. doi:10.1023/B:JOTS.0000014671.27856.7e

MacKinnon, D. P., Krull, J. L., \& Lockwood, C. M. (2000). Equivalence of the mediation, confounding, and suppression effect. Prevention Science, 1, 173-181. doi:10.1023/A:1026595011371

McMillen, J. C., \& Fisher, R. H. (1998). The perceived benefit scale: Measuring perceived positive life changes after negative events. Social Work Research, 22, 173-187. doi:10.1093/swr/22.3.173

McWhirter, B., Besett-Alesch, T., Horibata, J., \& Gat, I. (2002). Loneliness in high risk adolescents: The role of coping, self-esteem, and empathy. Journal of Youth Studies, 5, 69-84. doi:10.1080/13676260120111779

Muncer, S., \& Ling, J. (2006). Psychometric analysis of the Empathy Quotient scale (EQ). Personality and Individual Differences, 40, 1111-1119. doi:10.1016/j.paid.2005.09.020

Neff, L., \& Karney, B. (2005). Gender differences in social support: A question of skill or responsiveness? Journal of Personality and Social Psychology, 88, 79-90. doi:10.1037/0022-3514.88.1.79

O’Brien, T., DeLongis, A., Pomaki, G., Puterman, E., \& Zwicker, A. (2009). Couples coping with stress: The role of empathic responding. European Psychologist, 14, 18-28. doi:10.1027/1016-9040.14.1.18

Park, C., Cohen, L., \& Murch, R. (1996). Assessment and prediction of stress-related growth. Journal of Personality, 64, 71-105. doi:10.1111/j.1467-6494.1996.tb00815.x

Preacher, K. J., \& Hayes, A. F. (2008). Asymptotic and resampling strategies for assessing and comparing indirect effects in multiple mediator models. Behavior Research Methods, 40, 879-891. doi:10.3758/BRM.40.3.879

Putallaz, M., Hellstern, L., Sheppard, B. L., Grimes, C. L., \& Glodis, K. A. (1995). Conflict, social competence, and gender: Maternal and peer contexts. Early Education and Development, 6, 433-447. doi: $10.1207 / \mathrm{s} 15566935$ eed0604_ 8

Salo, J., Qouta, S., \& Punamäki, R. (2005). Adult attachment, posttraumatic growth and negative emotions among former political prisoners. Anxiety, Stress, and Coping, 18, 361-378. doi:10.1080/10615800500289524

Schultz, J., Tallman, B., \& Altmaier, E. (2010). Pathways to posttraumatic growth: The contributions of forgiveness and importance of religion and spirituality. Psychology of Religion and Spirituality, 2, 104-114. doi:10.1037/a0018454

Shirtcliff, E., Vitacco, M., Graf, A., Gostisha, A., Merz, J., \& ZahnWaxler, C. (2009). Neurobiology of empathy and callousness: Implications for the development of antisocial behavior. Behavioral
Sciences and the Law, 27, 137-171. doi:10.1002/bs1.862

Shrout, P. E., \& Bolger, N. (2002). Mediation in experimental and nonexperimental studies: New procedures and recommendations. Psychological Methods, 7, 422-445. doi:10.1037/1082-989X.7.4.422

Singer, T., Seymour, B., O’Doherty, J., Kaube, H., Dolan, R., \& Frith, C. (2004). Empathy for pain involves the affective but not sensory components of pain. Science, 303, 1157-1162. doi: $10.1126 /$ science. 1093535

Staub, E., \& Vollhardt, M. (2008). Altruism born of suffering: The roots of caring and helping after victimization and other trauma. American Journal of Orthopsychiatry, 78, 267-280. doi:10.1037/a0014223

Sullivan, K., Pasch, L., Johnson, M., \& Bradbury, T. (2010). Social support, problem solving, and the longitudinal course of newlywed marriage. Journal of Personality and Social Psychology, 98, 631644. doi: $10.1037 / \mathrm{a} 0017578$

Swickert, R., DeRoma, V. M., \& Saylor, C. F. (2004). The relationship between gender and trauma symptoms: A proposed mediational model. Individual Differences Research, 2, 203-213.

Swickert, R. J., \& Hittner, J. B. (2009). Social support coping mediates the relationship between gender and posttraumatic growth. Journal of Health Psychology, 14, 387-393. doi:10.1177/1359105308101677

Taylor, S., Klein, L., Lewis, B., Gruenwald, T., Gurung, R., \& Updegraff, J. (2000). Biobehavioral responses to stress in females: Tend-and-befriend, not flight-or-fight. Psychological Review, 107, 411-429. doi:10.1037/0033-295X.107.3.411

Tedeschi, R., \& Calhoun, L. (2004). Posttraumatic growth: Conceptual foundations and empirical evidence. Psychological Inquiry, 15, 1-18. doi:10.1207/s15327965pli1501_01

Toi, M., \& Batson, C. (1982). More evidence that empathy is a source of altruistic motivation. Journal of Personality and Social Psychology, 43, 281-292. doi:10.1037/0022-3514.43.2.281

Vishnevsky, T., Cann, A., Calhoun, L., Tedeshi, R., \& Demakis, G. (2010). Gender differences in self-reported posttraumatic growth: A meta-analysis. Psychology of Women Quarterly, 34, 110-120. doi:10.1111/j.1471-6402.2009.01546.x

Walker, S. (2005). Gender differences in the relationship between young children's peer-related social competence and individual differences in theory of mind. The Journal of Genetic Psychology, 166, 297-312. doi:10.3200/GNTP.166.3.297-312

Widows, M., Jacobsen, P., Booth-Jones, M., \& Fields, K. (2005). Predictors of posttraumatic growth following bone marrow transplantation for cancer. Health Psychology, 24, 266-273. doi:10.1037/0278-6133.24.3.266

Woike, B., \& Matic, D. (2004). Cognitive complexity in response to traumatic experiences. Journal of Personality, 72, 633-657. doi:10.1111/j.0022-3506.2004.00275.x 